\title{
Erratum to: Handbook of Ocean Wave Energy
}

\author{
Arthur Pecher and Jens Peter Kofoed $(\mathbb{D}$
}

\section{Erratum to:}

\section{A. Pecher and J.P. Kofoed (eds.), Handbook of Ocean Wave Energy, Ocean Engineering \& Oceanography 7, DOI 10.1007/978-3-319-39889-1}

The original version of the book was inadvertently published without the following corrections:

In Chap. 3, Fig. 3.13 was incorrect due to an error by the publisher and was replaced.

The numbering style has been changed from Chapter Content Separately to Chapter Content.

The spelling of the affiliation was corrected which should read as Aalborg University.

The erratum book has been updated with the changes.

The updated original online version for this book can be found at 10.1007/978-3-319-39889-1

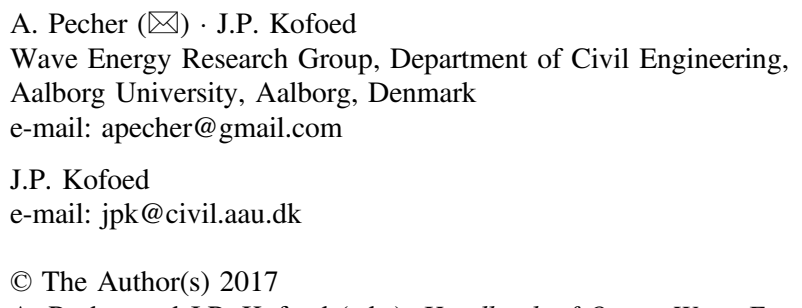

